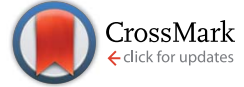

Cite this: RSC Adv., 2017, 7, 2264
Received 3rd November 2016 Accepted 1st December 2016

DOI: $10.1039 / c 6 r a 26255 d$

www.rsc.org/advances

\section{Fluorescein hydrazone-based supramolecular architectures, molecular recognition, sequential logic operation and cell imaging $\dagger$}

\author{
Kamini Tripathi, ${ }^{a}$ Abhishek Rai, ${ }^{a}$ Amarish Kumar Yadav, ${ }^{b}$ Saripella Srikrishna, ${ }^{\text {b }}$ \\ Niraj Kumari*a and Lallan Mishra*a
}

A fluorescein hydrazone (FDNS) is prepared by the coupling of fluorescein hydrazide with 3,5-dinitrosalicylaldehyde. It is well characterized using spectroscopic (IR, UV-visible, ${ }^{1} \mathrm{H},{ }^{13} \mathrm{C}$ NMR, ESI-MS) techniques and $\mathrm{X}$-ray crystallography. FDNS is embedded with several $\mathrm{H}$-bonding domains which provide interesting intra and inter molecular $\mathrm{H}$-bonded networks. Its crystal packing along the $b$ crystallographic axis using $\mathrm{H}$-bonding interactions provides a fascinating helical structure. It detects $\mathrm{Cu}^{2+}$ ions selectively over many relevant ions and displays a novel peak at $\lambda_{\max }=495 \mathrm{~nm}$. The significant enhancement in its fluorescence is observed with a peak at $\lambda_{\mathrm{em}}=517 \mathrm{~nm}$ on addition of $\mathrm{Hg}^{2+}$ ions, which is quenched upon the addition of $\mathrm{S}^{2-}$ ions. The sensing of $\mathrm{Hg}^{2+}$ ions by FDNS follow a hydrolysis pathway whereas the binding of $\mathrm{Cu}^{2+}$ ions with FDNS provides a colour change. The addition of a solution of tetrabutylammoniumcyanide in methanol to a corresponding solution of FDNS caused a turn to a green colour immediately. But on keeping the solution at room temperature for $72 \mathrm{~h}$, red coloured crystals are obtained. The crystals were authenticated by X-ray crystallography. It was found to be a new compound FKCN in which a tetrabutylammonium cation is co-crystallized with deprotonated FDNS. Its supramolecular assembly via $\mathrm{H}$-bonding provides an interesting ladder type architecture. FDNS displays chronological logic gate-based detection of several ions $\left(\mathrm{Cu}^{2+}, \mathrm{Hg}^{2+}, \mathrm{EDTA}\right.$, and $\left.\mathrm{S}^{2-}\right)$ at $\mathrm{ppm}$ levels. The real sample analysis, live cell imaging and portable paper strip based detection of $\mathrm{Cu}^{2+}$ and $\mathrm{Hg}^{2+}$ ions via an obvious colour change endows FDNS with great economic significance in recognition processes.

\section{Introduction}

The design and synthesis of adaptable molecules which can detect multiple analytes is of great significance as they provide the understanding of molecular interactions in recognition processes. Among several designed frameworks, fluorescein derivatives have extensively been exploited as structural scaffolds for optical probes due to their brilliant photophysical properties, such as longer absorption, emission wavelengths and large absorption coefficients. ${ }^{1-6}$ The spirolactam ring of fluorescein derivatives is a typical model for the design of molecular switches. Few interesting studies of the sensors for

\footnotetext{
${ }^{a}$ Department of Chemistry, Institute of Science, Banaras Hindu University, Varanasi, India. E-mail: nirajchem@gmail.com; Imishrabhu@yahoo.co.in; Fax: +91-5422368127; Tel: +91-542-6702449

${ }^{b}$ Department of Biochemistry, Institute of Science, Banaras Hindu University, Varanasi, India

$\dagger$ Electronic supplementary information (ESI) available: Spectral data crystallographic data and structure refinement parameters, selected bond lengths and bond angles, hydrogen bonds, $\pi \cdots \pi$ interactions. CCDC 1498576 and 1502946 for FDNS and FKCN. For ESI and crystallographic data in CIF or other electronic format see DOI: 10.1039/c6ra26255d
}

multiple-analytes have been reported earlier. ${ }^{7-14}$ In the area of molecular recognition, simultaneous detection of multiple ions has been the centre of attraction. In this context, toxicity of $\mathrm{Hg}^{2+}$ ions owes to its easy crossing of cell membrane barrier and warrants a simple design of its receptor. On the other hand, $\mathrm{Cu}^{2+}$ plays diverse physiological activities and its excess or scarcity leads Alzheimer's, Wilson's and Parkinson's diseases. ${ }^{15,16}$ Among the anions, cyanide and sulphide are considered very important toxicants and they are generated from several industrial sources. Therefore, a rapid method to detect multiple ions with a single optical probe accessible in environmental and biological systems is in great demand. ${ }^{17,18}$ The design of a logic device for the conversion of chemically encoded information into the optical signals has emerged as a demanding area of research. ${ }^{19,20}$

In this context, it has also been observed that such designed molecular systems can display several types of supramolecular architectures if they are embedded specially with $\mathrm{H}$ donors and $\mathrm{H}$-acceptor components. In fact, the area of crystal engineering has been enriched with several interesting organic compounds with stunning display of supramolecular architectures. The multiple hydroxyl group containing ligands have proven as 
perfect candidate as they know how to act as hydrogen donors and acceptors. The recognition at molecular level involves several non covalent interactions like hydrogen bonding, $\mathrm{CH}-\pi$ interaction as well as $\pi-\pi$ stacking together with hydrophobic forces. ${ }^{21}$ The fluorescein dye and its derivatives richly embedded with several $\mathrm{H}$-bonding domains are considered appropriate organic compounds for the construction of different type of supramolecular structures. In the present context, 3,5-dinitrosalicylaldehyde was selected as a coupling component as it was anticipated to impart the fluorescence enhancement of overall framework as compared to earlier used 5-nitrosalicylaldehyde. ${ }^{22}$

Thus, based on the above precedence, fluorescein hydrazide condensed with 3,5-dinitrosalicylaldehyde provided the desired compound (FDNS) which is characterized using full battery of physico chemical techniques and X-ray crystallography. As anticipated, it was empowered with the discriminatory recognition of $\mathrm{Cu}^{2+}$ and $\mathrm{Hg}^{2+}$ ions and it's FDNS- $\mathrm{Cu}^{2+}$ adduct acted as secondary sensor of $\mathrm{CN}^{-}$ions. The $\mathrm{H}$-bonding components embedded on its skeleton, enable the formation of intra and intermolecular interactions. These interactions lead interesting supramolecular assembly and provide helical structure. It also acts as a module for computing sequential logic operations.

\section{Experimental}

\subsection{Materials and methods}

All chemicals were obtained from industrial sources. The CE-440 Elemental analyzer is used for elemental analyses of C, $\mathrm{H}$, and N. Varian 3300 FT-IR and Shimadzu UV-1601 were used for recording their IR and UV-visible spectra, respectively. ${ }^{1} \mathrm{H}$ (500 MHz) and ${ }^{13} \mathrm{C}(100 \mathrm{MHz}) \mathrm{NMR}$ spectra were recorded via JEOL AL500 FT-NMR spectrometer. Perkin Elmer Fluorescence spectrophotometer is used for the measurement of fluorescence spectrum in aqueous : $\mathrm{MeOH}(8: 2, \mathrm{v} / \mathrm{v}$, HEPES buffer $(1 \mathrm{mM})$, $\mathrm{pH}$ 7.4) at room temperature. ESI-MS was obtained using a mass spectrophotometer of made WATERS Q-TOF Premier-HAB213. The yellow crystals of FDNS were obtained through slow evaporation of its solution in DMSO at room temperature. X-ray diffraction data were collected using Oxford diffraction XCALIBUR-EOS diffractometer with monochromated Mo $\mathrm{K}_{\alpha}$ radiation $(\lambda=0.71073 \AA)$. The data were solved by using SHELXS-97 Program ${ }^{23}$ whereas they were refined by full matrix least squares SHELXL-97. ${ }^{\mathbf{2 4}}$

\subsection{Synthesis}

The fluorescein hydrazone (FDNS) is synthesized by refluxing fluorescein hydrazide $(0.345 \mathrm{~g}, 1 \mathrm{mmol})$ and 3,5-dinitrosalicylaldehyde $(0.21 \mathrm{~g}, 1.1 \mathrm{mmol})$ in absolute ethanol (20 $\mathrm{mL}$ ), on water bath for $8 \mathrm{~h}$, under $\mathrm{N}_{2}$ atmosphere. A yellow precipitate was obtained, which was filtered and washed with ethanol to give desired fluorescein hydrazone (FDNS) in 75\% yields (Scheme 1). The yellow colour crystals of FDNS were developed by the slow evaporation of a solution of FDNS in DMSO at room temperature. $\mathrm{Mp}>200{ }^{\circ} \mathrm{C}$; FT-IR $\left(\mathrm{KBr}, \mathrm{cm}^{-1}\right)$ : 3333 (OH), 3082 (Ar-H), $1696(\mathrm{C}=\mathrm{O}), 1609(\mathrm{C}=\mathrm{N}), 1262(\mathrm{C}-\mathrm{O})$; ${ }^{1} \mathrm{H}$ NMR (500 MHz, DMSO-d 6 ): $\delta 9.93(\mathrm{~s}, 1 \mathrm{H}, \mathrm{OH}), 9.03(\mathrm{~s}, \mathrm{CH}=$
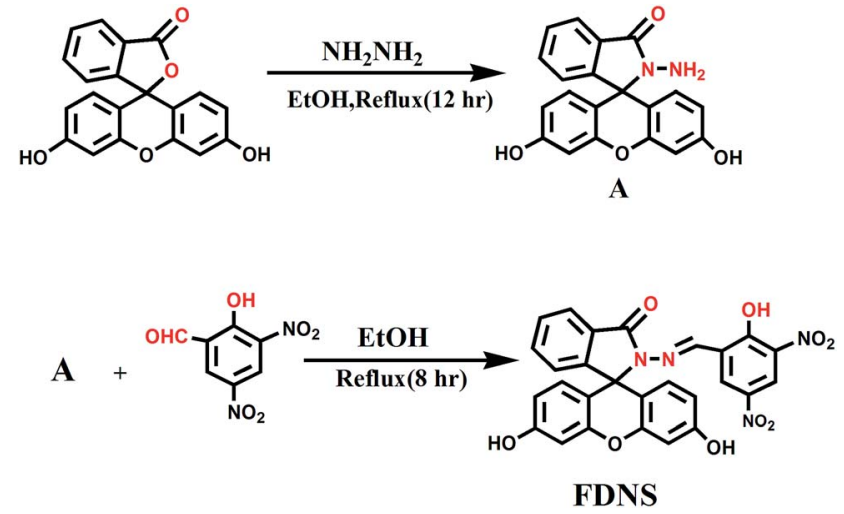

Scheme 1 Synthesis of FDNS.

$\mathrm{N}, 1 \mathrm{H}), 8.64$ (bs, 1H), 8.54 (bs, 1H), 7.97 (d, 1H, $J=8.0 \mathrm{~Hz}), 7.63$ $(\mathrm{m}, 2 \mathrm{H}), 7.14(\mathrm{~d}, 2 \mathrm{H}, J=7.5 \mathrm{~Hz}), 6.69(\mathrm{~s}, 2 \mathrm{H}), 6.55(\mathrm{~d}, 2 \mathrm{H}, J=$ 8.5), 6.47 (d, $2 \mathrm{H}, J=10.5) ;{ }^{13} \mathrm{C}$ NMR (100 MHz, DMSO-d ${ }_{6}$ ): 182.35, 174.19, 168.47, 165.67, 164.05, 158.74, 153.99, 147.35, 152.27, 145.40, 138.41, 135.20, 130.69, 123.69, 122.90, 113.10, 110.20, 104.10, 98.31, 65.01, 51.69; EI-MS $\mathrm{m} / \mathrm{z}$ 541.1003; elemental analysis (calcd\%) for $\mathrm{C}_{27} \mathrm{H}_{16} \mathrm{~N}_{4} \mathrm{O}_{9}$ : C, 60.00; H, 2.98; N, 10.37; found C, 59.91; H, 2.90; N, 10.17.

FKCN was synthesized by the addition of excess solution of tetrabutylammoniumcyanide to a solution of FDNS in methanol containing copper nitrate solution in methanol. Red colour crystals suitable for X-ray measurement were obtained. $\mathrm{Mp}>$ $200{ }^{\circ} \mathrm{C}$; FT-IR ( $\left.\mathrm{KBr}, \mathrm{cm}^{-1}\right): 3303(\mathrm{OH}), 2963-2873$ (aliphatic-H), $1702(\mathrm{C}=\mathrm{O}), 1602(\mathrm{C}=\mathrm{N}), 1263(\mathrm{C}-\mathrm{O}) ;{ }^{1} \mathrm{H}$ NMR $(500 \mathrm{MHz}$, DMSO- $\left.\mathrm{d}_{6}\right): \delta 9.91(\mathrm{~s}, 1 \mathrm{H}, \mathrm{OH}), 8.81(\mathrm{~s}, \mathrm{CH}=\mathrm{N}, 1 \mathrm{H}), 8.47(\mathrm{~s}, 1 \mathrm{H}$, Ar), 8.14 (s, 1H, Ar), 7.88 (s, 1H, Ar), 7.54 (m, 2H, Ar), 7.05 (d, 1H, Ar), 6.64 (s, 1H, Ar), 6.47 (m, 2H, Ar), 6.43 (m, 2H, Ar), 3.16 (m, $\left.8 \mathrm{H}, \mathrm{CH}_{2}\right), 1.55\left(\mathrm{~m}, 8 \mathrm{H}, \mathrm{CH}_{2}\right), 1.31\left(\mathrm{~m}, 8 \mathrm{H}, \mathrm{CH}_{2}\right), 0.92(\mathrm{~m}, 12 \mathrm{H}$, $\left.\mathrm{CH}_{3}\right) ;{ }^{13} \mathrm{C}$ NMR $\left(\mathrm{DMSO}_{6}\right)$ : 194.61, 163.64, 158.52, 151.90, 151.28, 145.04, 138.00, 133.83, 128.48, 127.61, 122.76, 112.36, $109.83,102.70,64.84,23.06,19.21,13.49$.

\subsection{Determination of binding constants}

The binding constant of the formation of $\mathrm{Cu}^{2+} / \mathrm{Hg}^{2+}$ complexes were evaluated using Benesi-Hildebrand (B-H) plot (eqn (1)). ${ }^{25}$

$$
1 /\left(A-A_{0}\right)=1 /\left\{K\left(A_{\max }-A_{0}\right) C\right\}+1 /\left(A_{\max }-A_{0}\right)
$$

The symbol $A_{0}$ and $A$ corresponds to absorbance of FDNS at $\lambda_{\max }=554 \mathrm{~nm}$ and absorbance observed at a particular concentration of the metal ion $(C)$, whereas $A_{\max }$ is obtained at $\lambda_{\max }=495 \mathrm{~nm}$, respectively. The apparent binding constant $K$ $\left(\mathrm{M}^{-1}\right)$, is calculated from the slope of the linear plot.

\subsection{Method for spectroscopic investigation}

The stock solution of FDNS $\left(1 \times 10^{-5} \mathrm{M}\right)$ was prepared in aqueous : $\mathrm{MeOH}(8: 2 \mathrm{v} / \mathrm{v})$ solution and solutions of metal ions $\left(1 \times 10^{-2} \mathrm{M}\right)$ were prepared using their nitrate salts in water. A solution of tetrabutylammoniumcyanide $\left(1 \times 10^{-2} \mathrm{M}\right)$ was 
prepared in distilled water. Before UV-visible and fluorescence measurements all samples were equilibrated for $1 \mathrm{~min}$.

\subsection{Real sample analysis of $\mathrm{Cu}^{2+}$ and $\mathrm{Hg}^{2+}$ ions}

The three water samples (river, pond and lake) were used to prepare the required samples after filtration. All the water samples $(3.0 \mathrm{~mL})$ were spiked independently with different concentrations $(0-10 \mu \mathrm{M})$ of $\mathrm{Cu}^{2+}$ and $\mathrm{Hg}^{2+}$ ions followed by the addition of FDNS $(10 \mu \mathrm{M})$ to corresponding solutions.

\subsection{Detection limit}

The limit of detection was evaluated by means of UV-visible and florescence titrations. The absorption and emission spectrum of FDNS was measured at 10 times, and the standard deviation of blank measurement was achieved. The graph of the UVvisible absorbance at $\lambda_{\max }=495 \mathrm{~nm}$ and florescence $\lambda_{\max }=$ $517 \mathrm{~nm}$ was plotted repetitively $v s$. the concentration of $\mathrm{Cu}^{2+}$ and $\mathrm{Hg}^{2+}$ ions to get the slope. The limit of detection was calculated using equation LOD $=3 \sigma / k$ where $\sigma$ is standard deviation of blank measurement. ${ }^{26}$

\subsection{Cell culture, compound treatments and fluorescence imaging}

Cervical cancer cell lines (ME-180) obtained from National Centre for Cell Science (NCCS), Pune, India, were cultured in Dulbecco's modified Eagle's medium (DMEM, HiMedia) supplemented with $10 \%$ FBS and $1 \times$ antibiotic cocktail in $\mathrm{CO}_{2}$ incubator at $37{ }^{\circ} \mathrm{C}$. For cell imaging experiment, the cultured cells were washed with $1 \times$ PBS followed by trypsinization for 2 min and collected in Eppendorf tube. Cells were incubated with FDNS $(10 \mu \mathrm{M})$ for $45 \mathrm{~min}$ at room temperature and in other set, cells were initially treated with FDNS $(10 \mu \mathrm{M})$ for $30 \mathrm{~min}$ followed by addition of $\mathrm{Hg}^{2+}(50 \mu \mathrm{M})$ for $15 \mathrm{~min}$, while control set was treated with solvent alone (methanol and water in $1: 9$ ratio). After incubation, cells were centrifuged at $2000 \mathrm{rpm}$ for $1 \mathrm{~min}$ and washed twice with $1 \times$ PBS for 2 min each. Cells were mounted in $1 \times$ PBS and images were captured with Nikon Ni-U fluorescence microscope using FITC filter-Ex-465-496, DM 505, BA 515-555. Fluorescence intensity was measured using NikonNIS-element BR software.

\section{Results and discussion}

The compound FDNS is characterized by IR, ${ }^{1} \mathrm{H}$ NMR, ${ }^{13} \mathrm{C}$ NMR, ESI-MS spectral data and elemental analysis. Its structure was further legitimate by X-ray crystallography and molecular structure (ORTEP diagram) is depicted in Fig. 1.

IR spectrum of FDNS displays a distinct peak at $\nu 1609 \mathrm{~cm}^{-1}$ assigned to $\nu(\mathrm{HC}=\mathrm{N})$ stretching vibration (Fig. S1 $\dagger$ ). Its ${ }^{1} \mathrm{H}$ and ${ }^{13} \mathrm{C}$ NMR spectrum are shown in Fig. S2 and $\mathrm{S} 3 \uparrow$ respectively and supports the existence of $\mathrm{CH}=\mathrm{N}$ group at $\delta 9.04 \mathrm{ppm}$ in solution. ESI-MS also supports the formation of FDNS with the peak at $m / z 541.1003$ corresponding to [FDNS $+\mathrm{H}]^{+}$(Fig. S4 $\dagger$ ). Appearance of a peak at $\delta 65.01 \mathrm{ppm}$ for spiro carbon in its ${ }^{13} \mathrm{C}$ NMR spectrum supported the presence of spiro-cyclic ring in its structure. ${ }^{27}$ The UV-visible spectrum of FDNS showed peak at

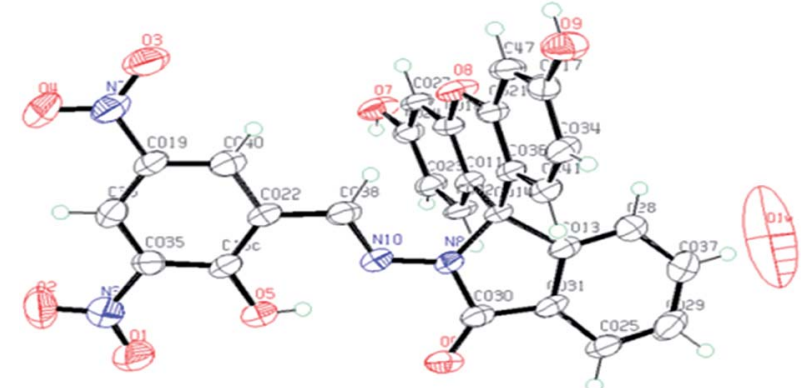

Fig. 1 Molecular structure (ORTEP diagram) of FDNS at 40\% probability level.

$\lambda_{\max }=401 \mathrm{~nm}\left(\varepsilon=25800 \mathrm{M}^{-1} \mathrm{~cm}^{-1}\right)$ designated to intramolecular charge transfer transition. Some structural parameters are presented in Table $\mathrm{S} 1 \uparrow$ whereas the selected bond distances $(\AA)$ and bond angles (deg) were presented in Table $\mathrm{S} 2 . \dagger$ The selected parameters for weak interactions are listed as Table S3. $\dagger$ It is quite interesting to visualise the molecule FDNS as a typical paddle-wheel type structure, having a dihedral angle of $85.62^{\circ}$ between two coordination planes (Fig. 2a). An intramolecular hydrogen bond formation between O5-H006 $\cdots \mathrm{N} 10$ could be seen as depicted in Fig. 2b. It provides a six-membered pseudo-ring consisting of N10-C038-C032-C16C-O5-H006 system. The bond distance between $\mathrm{H} 006 \cdots \mathrm{N} 10$ is found as $1.814 \AA$ with a bond angle of $147.17^{\circ}$ between O5-H006 $\cdots$ N10. The molecule is associated through two type of intermolecular $\mathrm{H}$-bond formation (Fig. 2c). One bond is formed between $-\mathrm{OH}$ (O9-H007) of one molecule and one of the nitro groups (O2-N3O1) of another molecule of FDNS. The second intermolecular $\mathrm{H}$ bond is formed between carbonyl group (C030-O6) of one FDNS
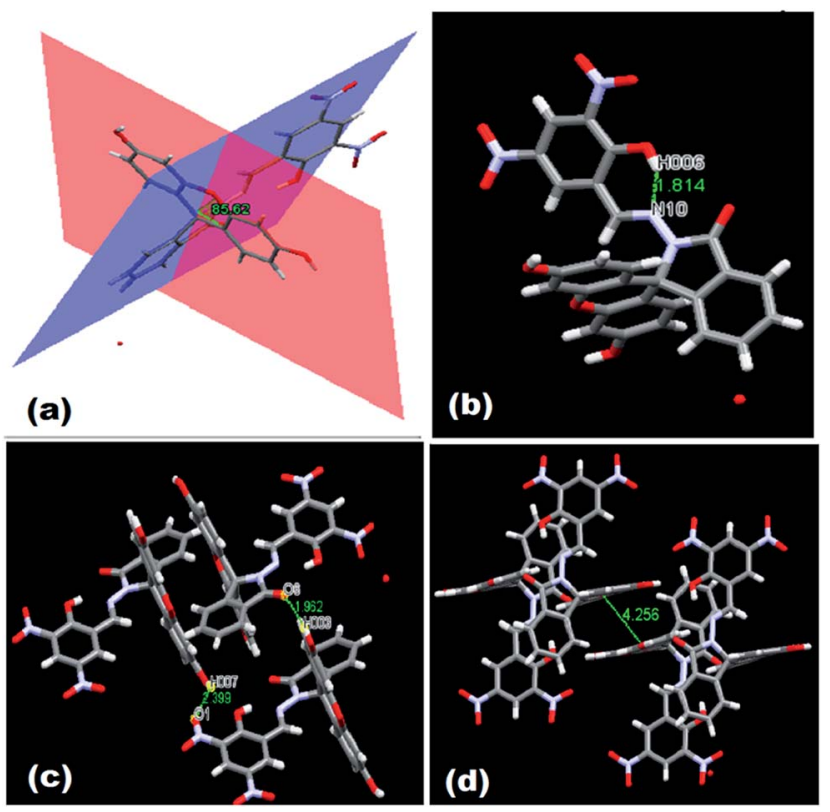

Fig. 2 Different structures of FDNS (a) paddle wheel structure (b) intra molecular $\mathrm{H}$-bonding, (c) inter molecular $\mathrm{H}$-bonding, and (d) $\pi-\pi$ stacking interaction. 

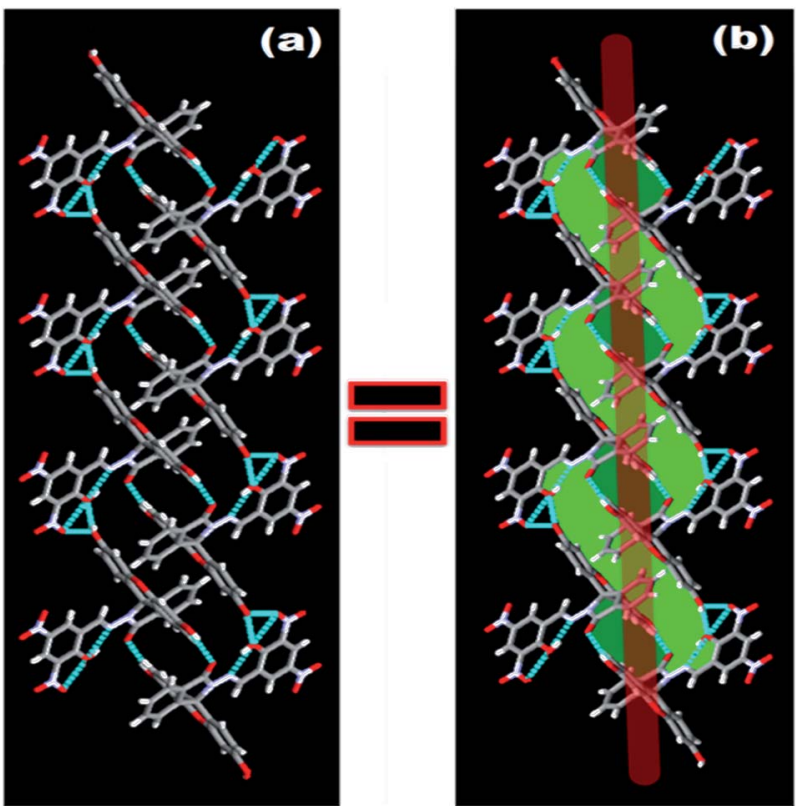

Fig. 3 The packing of FDNS along $b$ axis (a) and corresponding double helical structure (b).

molecule with a hydroxyl group (H003 $\cdots$ O 7 ) of other FDNS. A weaker aromatic stacking interaction between xanthene moieties of two FDNS molecules also occur at interplanar separation of $4.25 \AA$ as depicted in (Fig. 2d). The hydrogen bondings played significant role in the construction of supramolecular architecture propagating along different crystallographic axes. The packing structure of FDNS shows three different structures along three different axes. Along ' $a$ ' axis, it looks like a series of incandescent body connected via a single wire (Fig. S5†), whereas along ' $b$ ' as a double helical structure (Fig. 3) and along ' $c$ ' axis as a H-shaped structure (Fig. S6†).

\subsection{Spectral recognition of $\mathrm{Cu}^{2+}$ and $\mathbf{H g}^{2+}$ by FDNS}

Binding of several cations with FDNS were checked by adding their excess solution (10.0 eq.) separately to a solution of FDNS $\left(10^{-5} \mathrm{M}\right.$, aqueous : $\mathrm{MeOH}, 8: 2 \mathrm{v} / \mathrm{v}$, HEPES buffer $(1 \mathrm{mM}), \mathrm{pH}$ 7.4) (Fig. S7 $\dagger$ ). On addition of a fixed amount (10.0 equiv.) of $\mathrm{Cu}^{2+}$ ions to the FDNS, a momentous enrichment in absorbance at $\lambda_{\max }=495 \mathrm{~nm}$ was observed with a concomitant disappearance of the band at $\lambda_{\max }=401 \mathrm{~nm}$. It induces a clear colour change of FDNS solution from a yellow to light brown. However, the addition of other competitive metal ions $\left(\mathrm{Li}^{+}, \mathrm{Hg}^{2+}, \mathrm{Ca}^{2+}\right.$, $\mathrm{Cd}^{2+}, \mathrm{Fe}^{3+}, \mathrm{Na}^{+}, \mathrm{Al}^{3+}, \mathrm{Zn}^{2+}, \mathrm{Pb}^{2+}, \mathrm{Mg}^{2+}, \mathrm{Cu}^{2+}, \mathrm{Co}^{2+}, \mathrm{Ni}^{2+}$, and $\mathrm{Ag}^{+}$ ions) did not show any considerable colour change and spectral variation under the same conditions. It suggested a high selectivity of FDNS toward $\mathrm{Cu}^{2+}$ ions (Fig. S8 $\dagger$ ). The fluorescence response of FDNS with different cations was also studied as depicted in Fig. S9. $\uparrow$ The non fluorescent FDNS did not show any distinct change in its emission pattern on the addition $\mathrm{Cu}^{2+}$ ions. However, under the similar condition, a passionate fluorescence enhancement in presence of excess $\mathrm{Hg}^{2+}$ ions was observed with a peak at $\lambda_{\mathrm{em}}=517 \mathrm{~nm}$. It could be ascribed to the combinatorial effect of ring opening of FDNS and chelation of $\mathrm{Hg}^{2+}$ ions to it. The spectral pattern remains unbothered on the addition of several other competing metal ions.

\subsection{Spectral titrations}

The spectrophotometric titrations were performed to analyse the interaction of FDNS with $\mathrm{Cu}^{2+}$ ions at $25{ }^{\circ} \mathrm{C}$ in aqueous : MeOH ( $8: 2 \mathrm{v} / \mathrm{v}$, HEPES buffer(1 mM), pH 7.4). As shown in Fig. 4, a new absorption band centred at $\lambda_{\max }=495 \mathrm{~nm}$ gradually arises on the incremental addition of $\mathrm{Cu}^{2+}(0-1$ equiv. $)$ with concomitant change in the colour from yellow to light brown (inset of Fig. 4). An isobestic point is observed at $\lambda_{\max }=$ 382 and $448 \mathrm{~nm}$. The stoichiometric affiliation between FDNS and $\mathrm{Cu}^{2+}$ was found to be $1: 1$ based on the change in absorbance at $\lambda_{\max }=495 \mathrm{~nm}$. The fluorescent spectra as shown in Fig. 5, were obtained on excitation at $\lambda_{\mathrm{ex}}=495 \mathrm{~nm}$.

Free FDNS was found weak-fluorescent. However, on incremental addition of $\mathrm{Hg}^{2+}$ ions to FDNS solution, a strong fluorescence with a band centred at $\lambda_{\mathrm{em}}=517 \mathrm{~nm}$ was displayed. It was attributed to chelation enhanced fluorescence (CHEF) effect. ${ }^{28-30}$ The change in colour under UV light occurs as depicted in inset of Fig. 5. Thus, FDNS has very alluring "turnon" fluorescence selectivity, for detection of toxic $\mathrm{Hg}^{2+}$ ions. ${ }^{31-36}$ FDNS remains non fluorescent on the addition of $\mathrm{Cu}^{2+}$ ions owing to paramagnetic effect arising from spin-orbit coupling of the $\mathrm{Cu}^{2+}$ ions. ${ }^{36}$ Moreover, in case of absorbance, addition of $\mathrm{Cu}^{2+}$ ions followed an exponential increase (Fig. S10†) while in case of fluorescence, there is a linear increase on incremental addition of $\mathrm{Hg}^{2+}$ ions (Fig. S11†). The binding constant for $\mathrm{Cu}^{2+}$ and $\mathrm{Hg}^{2+}$ at $R^{2}=0.99$, computed using the Benesi-Hildebrand method are found as $2.55 \times 10^{5}$ and $4.79 \times 10^{4} \mathrm{M}^{-1}$ respectively. The corresponding graphs are shown in Fig. S12 and $\mathrm{S} 13, \dagger$ respectively. The maximum point at 0.5 for $\mathrm{Cu}^{2+}$ and $\mathrm{Hg}^{2+}$ in Job's plots also indicated that FDNS formed $1: 1$ complexes with $\mathrm{Cu}^{2+}$ and $\mathrm{Hg}^{2+}$ (Fig. S14 and S15†). The detection limit of

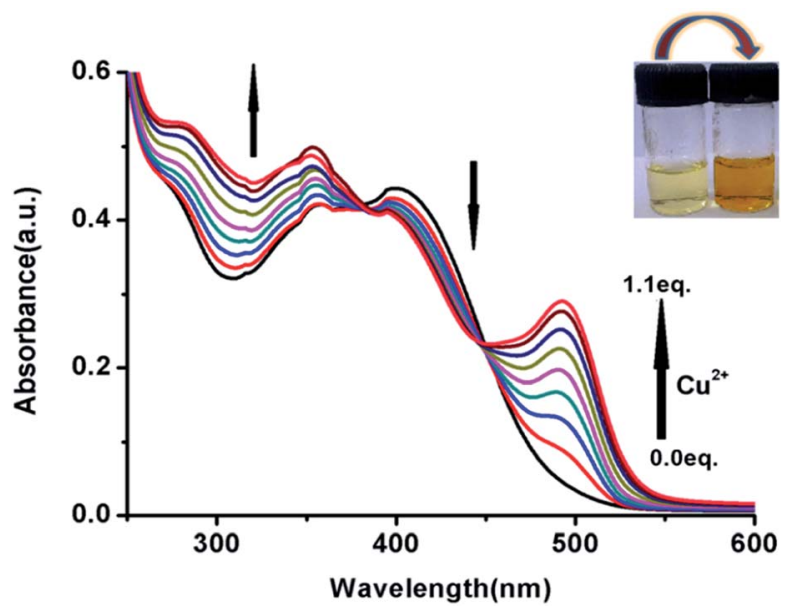

Fig. 4 Absorption spectral titrations of FDNS $(10 \mu \mathrm{M})$ in aqueous : $\mathrm{MeOH}(8: 2 \mathrm{v} / \mathrm{v})$ HEPES buffer ( $1 \mathrm{mM}, \mathrm{pH} 7.4)$ on the incremental addition of aqueous solution of $\mathrm{Cu}\left(\mathrm{NO}_{3}\right)_{2}$ (1.1 equiv.). Inset: visual change in the colour of FDNS solution in the presence of $\mathrm{Cu}^{2+}$ ions under normal light. 


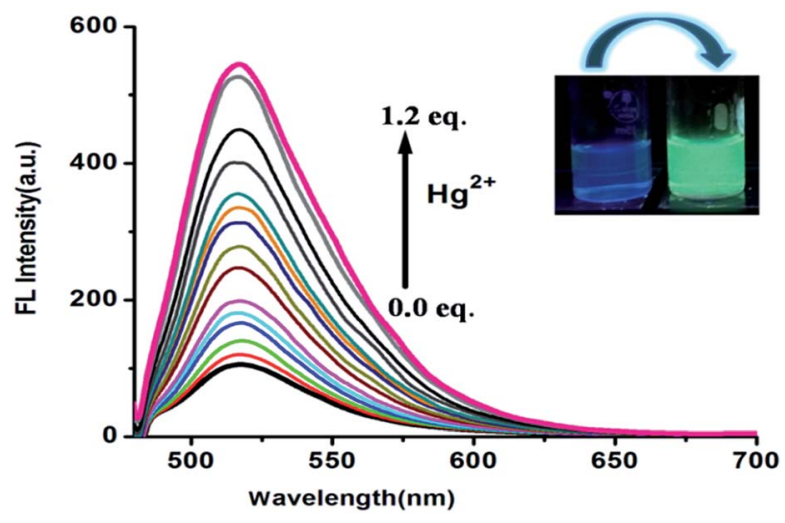

Fig. 5 Fluorescence spectral titrations of FDNS $(10 \mu \mathrm{M})$ in aqueous: $\mathrm{MeOH}(8: 2 \mathrm{v} / \mathrm{v}) \mathrm{HEPES}$ buffer $(1 \mathrm{mM}, \mathrm{pH} 7.4)$ on the incremental addition of $\mathrm{Hg}\left(\mathrm{NO}_{3}\right)_{2}$ (1.2 equiv.) $\lambda_{\text {ex }}=465 \mathrm{~nm}$. Inset: the colour change of FDNS solution in the presence of $\mathrm{Hg}^{2+}$ ions under UV light.

FDNS for $\mathrm{Cu}^{2+}$ and $\mathrm{Hg}^{2+}$ was found as $4.13 \times 10^{-7} \mathrm{M}$ and $2.50 \times$ $10^{-7} \mathrm{M}$ respectively, (Fig. S16 and S17 $\dagger$ ). It suggested that FDNS is an efficient system for monitoring traces of $\mathrm{Cu}^{2+}$ and $\mathrm{Hg}^{2+}$ ions. Thus, present probe turned out to be a multiple ion sensor exploiting both chromogenic and fluorogenic applications with a better detection limit as compared to earlier reported probe. ${ }^{22}$ Additionally, among several reported colorimetric probes, ${ }^{37}$ the present probe again turned out to be comparable with the detection limit and also in some case with stronger binding of $\mathrm{Cu}^{2+}$ ions. ${ }^{38}$ The quantum yield of FDNS (0.035) is enhanced upon binding with the $\mathrm{Hg}^{2+}$ ions (0.095) using fluorescein as a standard ( 0.5 in ethanol). However, some of the fluorescent probe reported earlier ${ }^{39}$ could not enhance the quantum yield on binding of $\mathrm{Hg}^{2+}$ ions. Thus, FDNS again turned out to be sensitive probe for $\mathrm{Hg}^{2+}$ ions.

\subsection{Selectivity of FDNS to $\mathrm{Cu}^{2+}$ and $\mathrm{Hg}^{2+}$ ions}

It is challenging to achieve selectivity of specific analyte over competing species in the area of the development of sensors. To appraise the selectivity of FDNS for $\mathrm{Cu}^{2+}$ and $\mathrm{Hg}^{2+}$ ions in reality, competition experiments were also carried out. FDNS was added separately to a solution of $\mathrm{Cu}^{2+}$ and $\mathrm{Hg}^{2+}$ ions in the existence of other cations, such as $\mathrm{Li}^{+}, \mathrm{Ca}^{2+}, \mathrm{Cd}^{2+}, \mathrm{Cr}^{3+}, \mathrm{Fe}^{3+}, \mathrm{K}^{+}$, $\mathrm{Na}^{+}, \mathrm{Al}^{3+}, \mathrm{Zn}^{2+}, \mathrm{Pb}^{2+}, \mathrm{Mg}^{2+}, \mathrm{Co}^{2+}, \mathrm{Ni}^{2+}, \mathrm{Ag}^{+}$. As shown in Fig. S18, $\uparrow$ for detection of $\mathrm{Cu}^{2+}$ ions, these ions did not reveal any noticeable interference in the absorption spectrum. Similarly, for detection of $\mathrm{Hg}^{2+}$ ions no significant interference was observed in the emission spectrum (Fig. S19†).

\subsection{Reversibility of FDNS for sensing $\mathrm{Cu}^{2+}$ and $\mathrm{Hg}^{2+}$}

Reversibility is significant parameter to check the practicability of a sensor. To realize the reversibility of the proposed FDNS- $\mathrm{Cu}^{2+}$ and $\mathbf{F H Y}-\mathrm{Hg}^{2+}$ species, EDTA and $\mathrm{S}^{2-}$ addition experiments were performed in the aqueous : $\mathrm{MeOH}$ solution, respectively. It was found that on addition of 2 equiv. EDTA solution to FDNS- $\mathrm{Cu}^{2+}$ adduct the absorbance decreased completely and reappears on further addition of $\mathrm{Cu}^{2+}$ ions
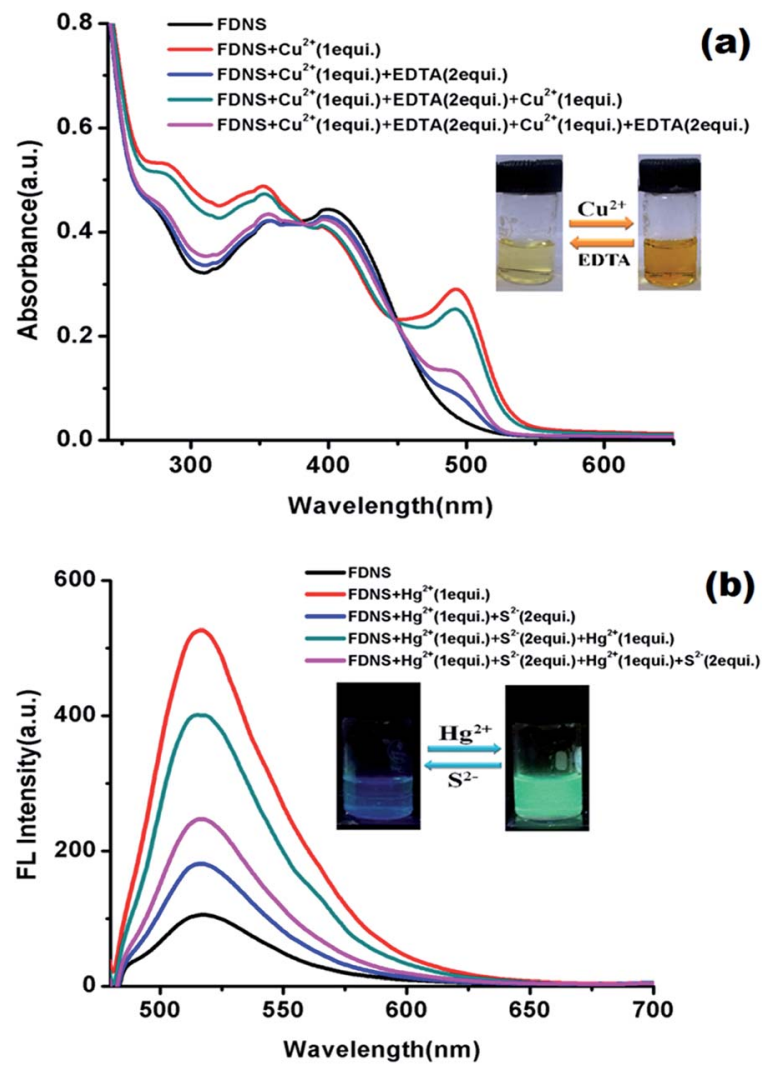

Fig. 6 Reversibility of FDNS evaluated by the alternative additions of (a) $\mathrm{Cu}^{2+}$ and EDTA (EDTA is 2 equiv. to $\mathrm{Cu}^{2+}$ ) alternately to the FDNS solution. Inset: visual change in the colour of FDNS solution in the presence of $\mathrm{Cu}^{2+}$ and EDTA under normal light and (b) $\mathrm{Hg}^{2+}$ and $\mathrm{S}^{2-}$ ions $\left(\mathrm{S}^{2-}\right.$ is 2 equiv. to $\mathrm{Hg}^{2+}$ ) alternately to the FDNS solution. Inset: the colour change of FDNS solution in the presence of $\mathrm{Hg}^{2+}$ and $\mathrm{S}^{2-}$ ions under UV light.

(Fig. 6a). It was repeated to six cycles (Fig. S20†). Similarly, the response of FHY- $\mathrm{Hg}^{2+}$ adduct with $\mathrm{Na}_{2} \mathrm{~S}$ was found reversible. After adding specific concentration of $\mathrm{Na}_{2} \mathrm{~S}$ (2 equiv.), fluorescence intensity was quenched (Fig. 6b) which was almost completely recovered on further addition of $\mathrm{Hg}^{2+}$ ions. This restoration capability indicates that FDNS could be re-used with suitable management.

It was interesting to observe a clear change in colour from brown to green on addition of tetrabutylammonium cyanide solution to FDNS- $\mathrm{Cu}^{2+}$ adduct, which finally change into red colour solution (Fig. S21†). In due course of time $(72 \mathrm{~h})$, red coloured crystals of a new compound (FKCN) were obtained. It was characterized using spectroscopic (IR, $\left.{ }^{1} \mathrm{H},{ }^{13} \mathrm{C} N M R\right)$ and Xray crystallography. It was observed that the tetrabutylammonium cation was co-crystallized with FDNS. The molecular structure (ORTEP diagram) of FKCN is depicted in Fig. 7 and its structural refinement parameters are given in Table S1. $\dagger$ IR spectrum of FKCN displays a distinct peak at $\nu 1603 \mathrm{~cm}^{-1}$ assigned to $\nu(\mathrm{HC}=\mathrm{N})$ vibration (Fig. $\mathrm{S} 22 \dagger$ ). ${ }^{1} \mathrm{H}$ spectrum (Fig. S23 $\dagger$ ) of FKCN further confirms the existence of $\mathrm{CH}=\mathrm{N}$ proton at $\delta 8.81 \mathrm{ppm}$. Its ${ }^{13} \mathrm{C}$ NMR spectrum (Fig. S24 $\dagger$ ) showed a peak at $\delta 64.84 \mathrm{ppm}$ and supports the presence of spiro carbon 


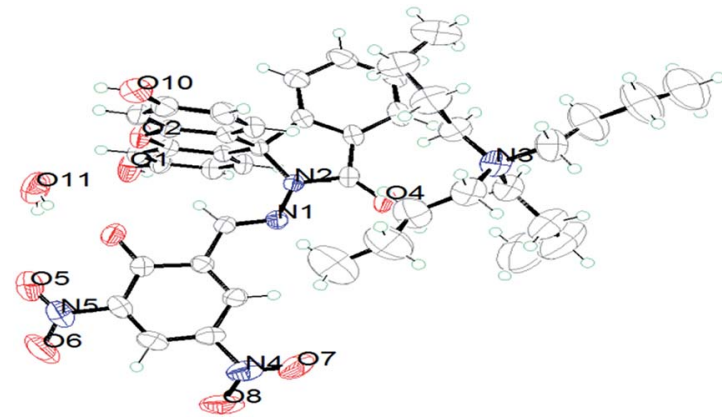

Fig. 7 Molecular structure (ORTEP) of FKCN at $40 \%$ probability level.

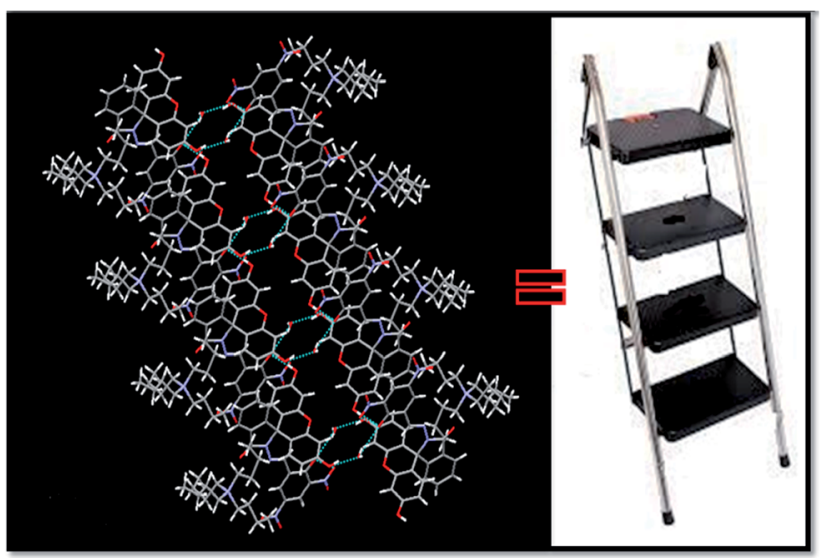

Fig. 8 Intermolecular hydrogen bonds between two molecules of FKCN via co-crystallised water molecule showing the formation of ladder structure.

in its structure. The UV-visible spectrum of FKCN showed peaks at $\lambda_{\max }=399 \mathrm{~nm}\left(\varepsilon=26600 \mathrm{M}^{-1} \mathrm{~cm}^{-1}\right)$ assigned to intramolecular charge transfer transition. It crystallizes in a triclinic crystal system with $P \overline{1}$ space group. In FKCN, dihedral angle between spirolactam and xanthene plane is found as 89.64(2) $)^{\circ}$ as depicted in Fig. S25. $\dagger$

Intermolecular hydrogen bonds between two molecules of FKCN via co-crystallised water molecule O11-H1w $\cdots \mathrm{O} 3$, O10$\mathrm{H} 10 \cdots \mathrm{O} 11$ stabilizes the crystal structure and forms supramolecular structure with cavity (Fig. S26 $\dagger$ ) while incorporation of another intermolecular hydrogen bonding of type O1-H010 $\cdots$ O3 between hydroxyl group (O1-H010) of a FKCN to carbonyl group of another neighbouring FKCN forms ladder like structure (Fig. 8).

\subsection{Probable mechanism of recognition of cations}

IR spectrum (Fig. S27†) of a solid isolated by the addition of $\mathrm{Cu}^{2+}$ ions to FDNS, showed major peaks at 1614.58 and 1645.8 $\mathrm{cm}^{-1}$. These peaks were assigned to $\nu(\mathrm{CH}=\mathrm{N})$ and $\nu(\mathrm{C}=\mathrm{O})$ respectively and shifted significantly as compared to peak observed for free FDNS. It supported that both groups of FDNS had coordinated with $\mathrm{Cu}^{2+}$ ion. The ESI-MS data of this adduct displayed a peak at $m / z 639.0066$ (Fig. S28 $\dagger$ ) which corresponds to the parent ion as $\left[\mathbf{F D N S}+\mathrm{Cu}^{2+}+2 \mathrm{H}_{2} \mathrm{O}\right]+1$. It further

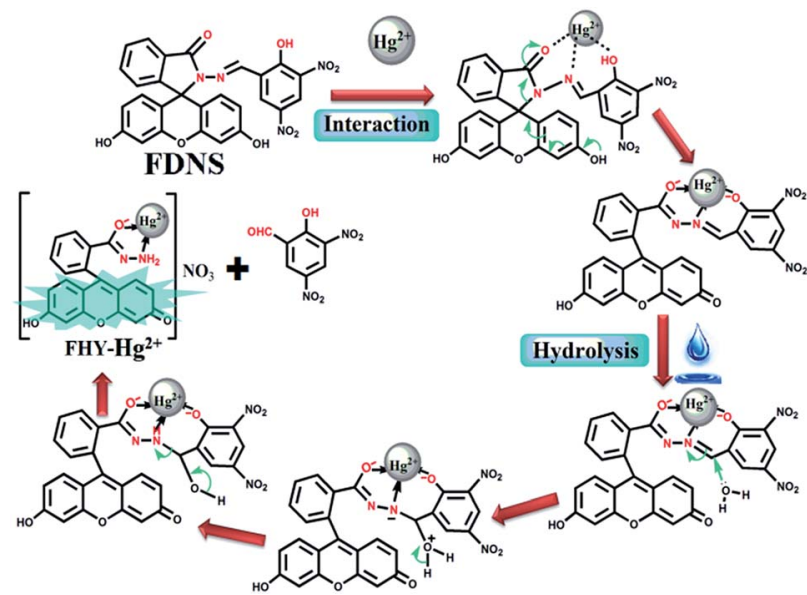

Scheme 2 Plausible mechanism for interaction of FDNS with $\mathrm{Cu}^{2+}$ ions and tetrabutylammonium cyanide.

supported the formation of a $1: 1$ copper adduct as evidenced from the absorption titrations. ${ }^{\mathbf{4 0 , 4 1}}$ The isolation of FKCN supported that FDNS- $\mathrm{Cu}^{2+}$ adduct interact with tetrabutylammonium cyanide via displacement approach as shown in Scheme 2. The binding of FDNS with $\mathrm{Hg}^{2+}$ ions was substantiated by its ${ }^{1} \mathrm{H}$ NMR titrations in a mixture of DMSO- $\mathrm{d}_{6}$ and $\mathrm{D}_{2} \mathrm{O}$. As shown in Fig. $\mathrm{S} 29, \dagger$ on the incremental addition of $\mathrm{Hg}^{2+}$, the imine proton $(\mathrm{CH}=\mathrm{N})$ shifted from $\delta 9.03$ to $9.23 \mathrm{ppm}$. It supported the coordination of $\mathrm{Hg}^{2+}$ to FDNS. The phenolic proton $(\mathrm{OH})$ of FDNS also moved to downfield by $\delta=0.29 \mathrm{ppm}$ (9.93 to $10.12 \mathrm{ppm}$ ) and finally disappeared. Interestingly, a new peak emerged at $\delta=10.42 \mathrm{ppm}$. It was assigned to an aldehyde proton. The above data imply that $\mathrm{Hg}^{2+}$ ion may first coordinated to the FDNS and then results in its hydrolysis. The ESI-MS of solid thus obtained gave a peak at $m / z=544.4615$ (Fig. S30 $\dagger$ ). It supported the formation of fluorescein hydrazide (FHY) $-\mathrm{Hg}^{2+}$ adduct, ${ }^{\mathbf{4 2 - 4 4}}$ further supported by its IR spectrum (Fig. S31†). Thus, based on these observations, a tentative mechanism of binding of $\mathrm{Hg}^{2+}$ ions to FDNS is proposed as shown in Scheme 3 .

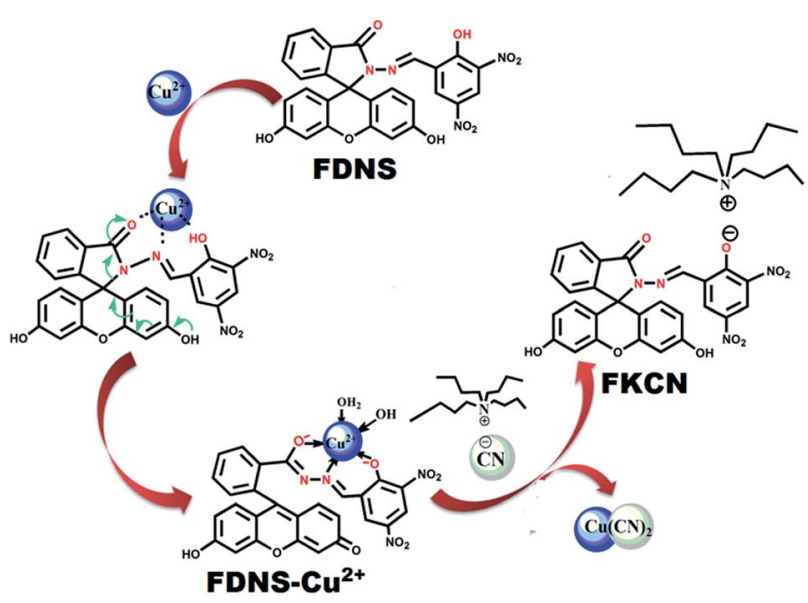

Scheme 3 Plausible mechanism for interaction of FDNS with $\mathrm{Hg}^{2+}$ ions. 


\section{6. $\quad$ pH effects on sensing by FDNS}

To check the sensing ability of FDNS at physiological level, $\mathrm{pH}$ effect of free FDNS and FDNS- $\mathrm{Cu}^{2+} / \mathrm{Hg}^{2+}$ adducts on the absorption and emission spectra were recorded over a wider range of $\mathrm{pH}$ (2.0-12.0). It was observed that the solution of FDNS showed insignificant absorption and emission in $\mathrm{pH}$ range 2.0-6.0; signifying that the FDNS was stable over this $\mathrm{pH}$ range. ${ }^{45}$ But as depicted in Fig. S32(a), $\dagger$ an intense absorption was observed after $\mathrm{Cu}^{2+}$ ions addition to FDNS solution. (pH 7.0 or more.)

Similarly, the fluorescence intensity of FHY- $\mathrm{Hg}^{2+}$ assembly also increases in the region of $\mathrm{pH} 7.0-12.0$ as depicted in Fig. S32(b). $\uparrow$ Thus, the response behaviour of FDNS separately to $\mathrm{Cu}^{2+}$ and $\mathrm{Hg}^{2+}$ ions could be studied under physiological conditions.

\subsection{Time-dependence detection process of $\mathrm{Cu}^{2+}$ and $\mathrm{Hg}^{2+}$}

The reaction time profile of FDNS separately with $\mathrm{Cu}^{2+}$ and $\mathrm{Hg}^{2+}$ ions are also studied. The kinetics of the reaction was complete within 40 and 25 seconds for $\mathrm{Cu}^{2+}$ and $\mathrm{Hg}^{2+}$ respectively. It showed that this probe react very rapidly with selective ions under the experimental conditions as shown in Fig. S33(a) and S33(b), $\uparrow$ respectively.

\subsection{Sequential logic gate operations}

Sequential circuits useful for the memory devices, function via feedback loop where one of the output obtained is used as the input and recognised as the 'memory element'. ${ }^{46}$ Thus, a sequential logic circuit is designed on the basis of $\mathrm{Cu}^{2+}$ and EDTA as chemical inputs which are designated as input A and input $\mathrm{B}$. The absorption at $\lambda_{\max }=495 \mathrm{~nm}$ and visual detection are considered as OUT1 and OUT2, respectively. A value of 0.12 was calculated as threshold value of OUT1 as depicted in Fig. S34. $\dagger$ A logic circuit having two inputs (input A and input B) and two outputs have been constructed and the concerned truth table is shown in Fig. 9. Furthermore, the switchability of FDNS controlled by $\mathrm{Hg}^{2+}$ and $\mathrm{S}^{2-}$ also commune information as two inputs and two outputs. The fluorescence signal at $517 \mathrm{~nm}$ functions as output 1 and the colour change of FDNS after addition of $\mathrm{Hg}^{2+}$ in UV light as output 2 and corresponding sequential logic circuits are depicted in Fig. S35 and S36. $\dagger$ A value of 200 as threshold value was fixed as OUT1 at $\lambda_{\mathrm{em}}=$

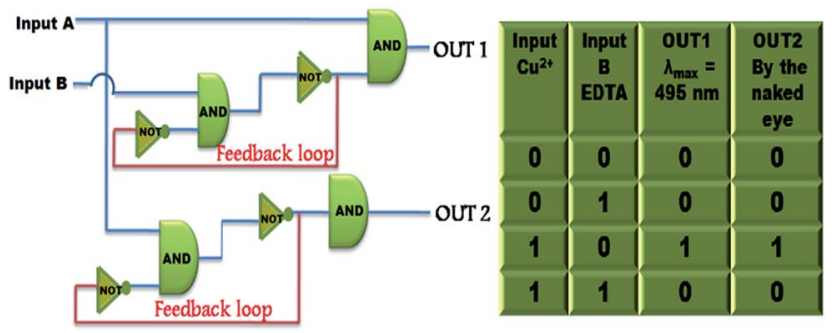

Fig. 9 Truth table and sequential logic circuits displaying memory units with two inputs (input $\mathrm{A}\left(\mathrm{Cu}^{2+}\right)$ and input $\mathrm{B}$ (EDTA)) and two outputs in the presence of chemical inputs.

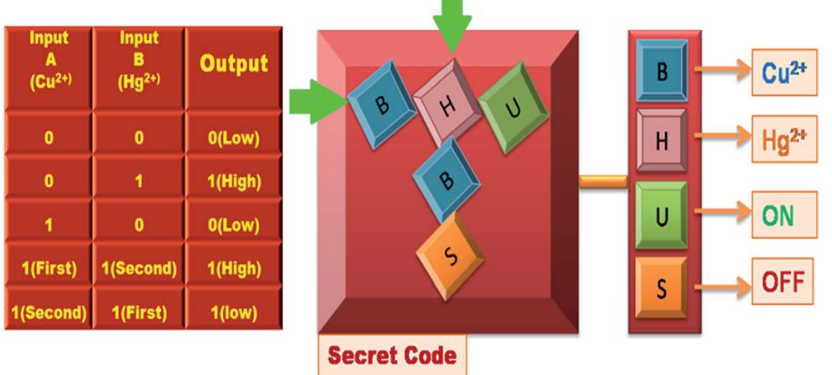

Fig. 10 Schematic representation of keypad locks and truth table of lock to access a secret code by observing the fluorescence at $517 \mathrm{~nm}$ with different inputs.

$517 \mathrm{~nm}$ for the fluorescence intensity. ' 1 ' is denoted for the fluorescence intensity greater than threshold value and ' 0 ' is represented for the intensity lower than the threshold value which corresponds to the 'ON' and 'OFF' states of the readout signals.

This system is also utilized for the construction of a security keypad lock depending on the sequential addition of $\mathrm{Cu}^{2+}$ and $\mathrm{Hg}^{2+}$ as inputs 1 and 2 respectively (Fig. S37†). The receptor FDNS shows no significant emission band at $517 \mathrm{~nm}$ in the absence of any chemical input hence output is 0 (OFF-state). The addition of $\mathrm{Cu}^{2+}$ to FDNS gives the output ' 0 ' (OFF-state) but it is reversed to ' 1 ' (ON-state) with the chronological addition of another input $\mathrm{Hg}^{2+}$. However, on changing the input sequence, $\mathrm{Hg}^{2+}$ as the first input with subsequent addition of $\mathrm{Cu}^{2+}$ as second input, the fluorescence intensity is observed below its threshold limit, thus output is represented as zero. Inputs $\mathrm{Cu}^{2+}$ and $\mathrm{Hg}^{2+}$ were represented as ' $\mathrm{B}$ ' and ' $\mathrm{H}$ ' respectively. There are two possibilities of inputs sequence: (a) addition of ' $\mathrm{B}$ ' followed by ' $\mathrm{H}$ ' where the receptor FDNS causes emission above threshold limit at $\lambda_{\mathrm{em}} 517 \mathrm{~nm}$ and this 'ON' state is assigned by ' $U$ ' which generate a secret code 'BHU'. In the reverse sequence, ' $\mathrm{H}$ ' is followed by ' $\mathrm{B}$ ', the fluorescence at $517 \mathrm{~nm}$ get quenched which is 'OFF' state and is denoted by ' $\mathrm{S}$ '. This sequence (HBS) failed to open the keypad lock. Hence, for the construction of the molecular keypad lock, 'BHU', inputs in specific sequence is essential. The schematic representation of keypad lock with corresponding truth table is depicted in Fig. 10.

More than 700 different combinations are observed by the use of numerical digits (0-9) and letters (A-Z) as 'PIN' in a twodigit password. ${ }^{47}$ Thus, unlocking the keypad lock becomes more complex which substantially enhances the security of the devices at molecular level. Thus, keypad lock can be unlocked only by the users who know the correct passwords.

\subsection{Role of FDNS in the analysis of $\mathrm{Cu}^{2+}$ and $\mathrm{Hg}^{2+}$ ions in water samples}

The role of FDNS for analysis of $\mathrm{Cu}^{2+}$ and $\mathrm{Hg}^{2+}$ ions in natural water were done by using proof-of-concept experiments without any prior sanitization. ${ }^{\mathbf{4 8}}$ Three water sample were collected from the different sources such as River Ganga (Assi), pond 
(Durgakund) and lake (Motijheel), all from Varanasi City, India. The solution of $\mathrm{Hg}\left(\mathrm{NO}_{3}\right)_{2}(0-10 \mu \mathrm{M})$ were spiked into these samples followed by addition of FDNS $(10 \mu \mathrm{M})$. A good linear curve was obtained between fluorescence intensity versus concentration of $\mathrm{Hg}^{2+}$ in the range of 2-10 $\mu \mathrm{M}$ (Fig. S38†). This clearly shows the potential relevance of FDNS for detection of $\mathrm{Hg}^{2+}$ ions in ecological water (Table S4 $\dagger$ ). Similarly, nitrate salt of $\mathrm{Cu}^{2+}$ ions $(0-10 \mu \mathrm{M})$ were spiked into the water samples solution followed by the addition of FDNS $(10 \mu \mathrm{M})$. Here also a linear graph between the absorption and the $\mathrm{Cu}^{2+}$ ion concentration in the range of $2-8 \mu \mathrm{M}$ (Fig. S39 $\dagger$ ). The data are presented Table S5. $\uparrow$ The experimental results suggested FDNS is relevant for effective analysis of $\mathrm{Cu}^{2+}$ or $\mathrm{Hg}^{2+}$ ions in natural water sources.

\subsection{Fast track detection of $\mathrm{Cu}^{2+}$ and $\mathrm{Hg}^{2+}$ ions}

To ensure the cleanliness of the drinking water and consumable food stuffs in remote places is a great challenge now days. Therefore, for on-site detection of $\mathrm{Cu}^{2+}$ and $\mathrm{Hg}^{2+}$ ions a manageable test strips were equipped, as they did not need any complicated equipments. Since, for this filter-paper strips were first soaked in FDNS solution and then air dried. After that filter-paper dipped in a $\mathrm{Cu}^{2+}$ solution (1 equiv.). A distinct visible light brown colour change was observed immediately as shown in Fig. 11a. The test-strips change its colour to fluorescent green under UV light in the presence of $\mathrm{Hg}^{2+}$ ion only (Fig. 11b). This makes the probes pretty useful for quick on-site detection of metal ions in real samples. ${ }^{49}$

\subsection{Live cell imaging of FDNS and detection of $\mathbf{H g}^{2+}$ ions in cervical cancer cell lines}

The uptake of FDNS by ME-180 cervical cancer cells is detected by fluorescence microscopy. FDNS treated live cells showed green fluorescence throughout the cells while control treated with solvent has no fluorescence (Fig. 12A and B).

Interestingly, FDNS mediated fluorescence was enhanced about 1.5 folds upon the addition of mercury $\left(\mathrm{Hg}^{2+}\right)$ (Fig. 12C). Magnified bright field images as depicted in Fig. 12D-F showed that cells are intact. The Fig. $12 \mathrm{H}$ and I show that compound is distributed throughout the cell and their intensity graph is

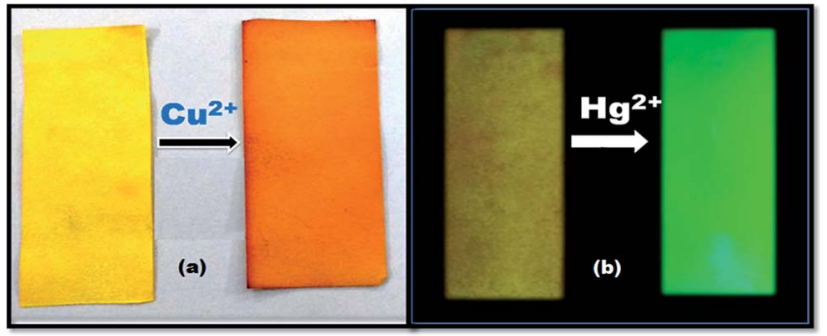

Fig. 11 (a) Naked eye detection on a piece of paper soaked with FDNS: from left to right FDNS (blank); FDNS $+\mathrm{Cu}^{2+}$ (b) the variation of the color of FDNS coated on filter paper before (left) and after treatment with $\mathrm{Hg}^{2+}$ (right) under UV excitation light.
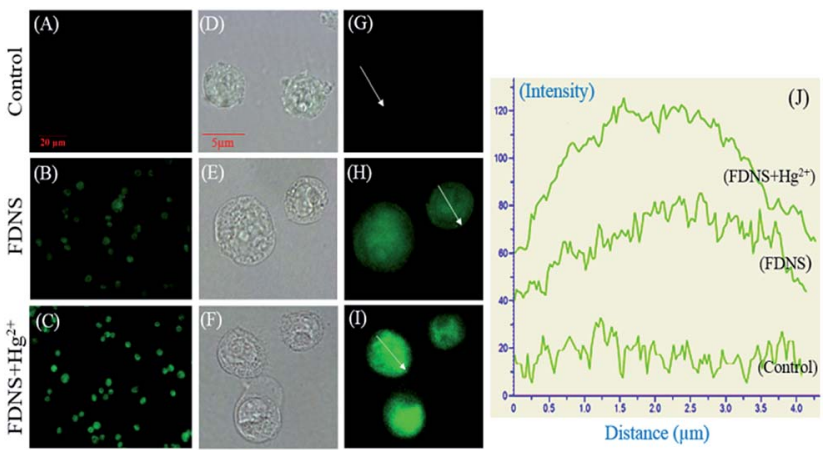

Fig. 12 Fluorescence images of ME-180 cervical cancer cells. (A) Control-cells (B) cells treated with $10 \mu \mathrm{M}$ FDNS and (C) FDNS treated cells in presence of $50 \mu \mathrm{M} \mathrm{Hg}^{2+}$. Magnified bright field images (D-F) show intact ME-180 cells and their respective fluorescence images $(G-I)$ show the presence of compound throughout the cells. Intensity graph (J) of cells (white-arrow) show relative fluorescence intensity for respective set of experiments. Scale bar in panel A-C is $20 \mu \mathrm{m}$ while 5 $\mu \mathrm{m}$ in $\mathrm{D}-\mathrm{I}$.

depicted in Fig. 12J. Hence, compound FDNS has wider permeability in ME-180 cervical cancer cells.

\section{Conclusions}

In summary, fluorescein hydrazone FDNS is synthesized by the condensation of 3,5-dinitrosalicylaldehyde with fluorescein hydrazide. It is effectively characterized using spectroscopic techniques and further supported by its X-ray crystallography. This molecule empowers the formation of interesting supramolecular structures via intermolecular H-bonding. FDNS exhibits a colorimetric response to $\mathrm{Cu}^{2+}$ ions with naked eye visibility followed by spectral titrations without any interference from several relevant metal ions. The addition of a solution of tetrabutylammoniumcyanide in methanol to a corresponding solution of FDNS- $\mathrm{Cu}^{2+}$ ensemble enables it as a secondary sensor of $\mathrm{CN}^{-}$ions and provides a novel organic compounds FKCN containing deprotonated FDNS co-crystallized with tetrabutylammonium cation. The $\mathrm{Hg}^{2+}$ and $\mathrm{Cu}^{2+}$ are selectively detected in the presence of several other metal ions with a detection limits of $4.13 \times 10^{-7} \mathrm{M}$ and $2.50 \times 10^{-7} \mathrm{M}$, respectively. The sensing mechanisms of FDNS for $\mathrm{Cu}^{2+}$ ions follows opening of spirolactam ring on its binding to FDNS. However, binding of $\mathrm{Hg}^{2+}$ ions to FDNS leads hydrolysis of $\mathrm{CH}=\mathrm{N}$ group bringing "turn on" fluorescence. The other potential applications of FDNS involves its uses as memory device, paper strip tests for the analysis of $\mathrm{Cu}^{2+}$ and $\mathrm{Hg}^{2+}$ ions in the contaminated samples. The live cell imaging also promotes its application in real world.

\section{Acknowledgements}

The financial assistance from DST (DST/INSPIRE FACULTY AWARD/2012, N. K.), UGC-BSR Faculty Fellowship (LM), and Banaras Hindu University fellowship (K. T.), are gratefully acknowledged. 


\section{References}

1 A. Ajaya ghosh, P. Carol and S. Sreejith, J. Am. Chem. Soc., 2005, 127, 14962.

2 J. W. Lee, H. S. Jung, P. S. Kwon, J. W. Kim, R. A. Bartsch, Y. Kim, S. Kim and J. S. Kim, Org. Lett., 2008, 10, 3801.

3 L. Xue, Q. Liu and H. Jiang, Org. Lett., 2009, 11, 3454.

4 M. Leermakers, W. Baeyens, P. Quevauviller and M. Horvat, Trends Anal. Chem., 2005, 24, 383.

5 C. C. Huang and H. T. Chang, Anal. Chem., 2006, 78, 8332.

6 S. Cai, Y. Lu, S. He, F. Wei, L. Zhao and X. Zeng, Chem. Commun., 2013, 49, 822.

7 T. Hirano, K. Kikuchi, Y. Urano, T. Higuchi and T. Nagano, J. Am. Chem. Soc., 2000, 122, 12399.

8 G. K. Walkup, S. C. Burdette, S. J. Lippard and R. Y. Tsien, J. Am. Chem. Soc., 2000, 122, 5644.

9 T. Hirano, K. Kikuchi, Y. Urano, T. Higushi and T. Nagano, Angew. Chem., Int. Ed., 2000, 39, 1052.

10 S. C. Burdette, G. K. Walkup, B. Spingler, R. Y. Tsien and S. J. Lippard, J. Am. Chem. Soc., 2001, 123, 7831.

11 K. R. Gee, Z. L. Zhou, W. J. Qian and R. Kennedy, J. Am. Chem. Soc., 2002, 124, 776.

12 S. C. Burdette, C. J. Frederickson, W. Bu and S. J. Lippard, J. Am. Chem. Soc., 2003, 125, 1778.

13 M. Suresh, A. Ghosh and A. Das, Chem. Commun., 2008, 44, 3906.

14 W. J. Shi, J. Y. Liu and D. K. P. Ng, Chem.-Asian J., 2012, 7, 196.

15 K. J. Barnham, C. L. Masters and A. I. Bush, Nat. Rev. Drug Discovery, 2004, 3, 205.

16 E. Gaggelli, H. Kozlowski, D. Valensin and G. Valensin, Chem. Rev., 2006, 106, 1995.

17 X. Zeng, L. Dong, C. Wu, L. Mu, S. F. Xue and Z. Tao, Sens. Actuators, B, 2009, 141, 506.

18 L. Tang, F. Li, M. Liu and R. Nandhakumar, Spectrochim. Acta, Part A, 2011, 78, 1168.

19 N. Sharma, S. I. Reja, V. Bhalla and M. Kumar, Dalton Trans., 2014, 43, 15929.

20 H. Y. Lee, K. M. K. Swamy, J. Y. Jung, G. Kim and J. Yoon, Sens. Actuators, B, 2013, 182, 530.

21 R. Prajapati, L. Mishra, S. J. Grabwoski, G. Govil and S. K. Dubey, J. Mol. Struct., 2008, 879, 1.

22 Y. Yang, F. Huo, C. Yin, Y. Chu, J. Chao, Y. Zhang, J. Zhang, S. Li, H. Lv, A. Zheng and D. Liu, Sens. Actuators, B, 2013, 177, 1189.

23 G. M. Sheldrick, SHELXS-97 Program for the Solution of Crystal Structures, University of Göttingen, Göttingen, Germany, 1997.
24 G. M. Sheldrick, Phase annealing in SHELX-90, Acta Crystallogr., Sect. A: Found. Crystallogr., 1990, 46, 467.

25 H. A. Benesi and J. H. Hildebrand, J. Am. Chem. Soc., 1949, 71, 2703.

26 A. Hakonen Plasmon, Anal. Chem., 2009, 81, 4555.

27 D. Wang, X. Xiang, X. Yang, X. Wang, Y. Guo, W. Liu and W. Qin, Sens. Actuators, B, 2014, 201, 246.

28 E. M. Nolan and S. J. Lippard, Chem. Rev., 2008, 108, 3443.

29 A. Tamayo, B. Pedras, C. Lodeiro, L. Escriche, J. Casabo,

L. Capelo, B. Covelo, R. Kiveka and R. Sillanpa, Inorg. Chem., 2007, 46, 159.

30 Y. Zhang, Y. Yang, J. Hao, C. Yin, F. Huo, J. Chao and D. Liu, Spectrochim. Acta, Part A, 2014, 132, 27.

31 Y. Yang, K. Yook and J. Tae, J. Am. Chem. Soc., 2005, 1, 16760.

32 G. Zhang, D. Zhang, S. Yin, X. Yang, Z. Shuai and D. Zhu, Chem. Commun., 2005, 6, 2161.

33 X. Guo, X. Qian and L. Jia, J. Am. Chem. Soc., 2004, 126, 2272. 34 G. Hennrich, W. Walther, U. Resch-genger and H. Sonnenschein, Inorg. Chem., 2001, 40, 641.

35 Y. Zhao, Z. Lin, C. He, H. Wu and C. Duan, Inorg. Chem., 2006, 45, 10013.

36 A. P. De Silva, H. Q. N. Gunarante, T. Gunnlaugsson, A. J. M. Huxley, C. P. McCoy, J. T. Rademacher and T. E. Rice, Chem. Rev., 1997, 97, 1515.

37 X. Wu, X. Gong, W. Dong, J. Ma, J. Chao, C. Li, L. Wang and C. Dong, $R S C A d v ., 2016,6,59677$ and references therein.

38 H. M. Chawla, R. Shukla and S. Pandey, Tetrahedron Lett., 2013, 54, 2063.

39 E. M. Nolan, M. E. Racine and S. J. Lippard, Inorg. Chem., 2006, 45, 2742.

40 Z. Q. Guo, W. H. Zhu, L. J. Shen and H. Tian, Angew. Chem., 2007, 119, 5645.

41 J. Mao, L. N. Wang, W. Dou, X. L. Tang, Y. Yan and W. S. Liu, Org. Lett., 2007, 9, 4567.

42 H. Cheng and Y. Qian, RSC Adv., 2015, 5, 82887.

43 H. A. Benesi and J. H. Hildebrand, J. Am. Chem. Soc., 1949, 71, 2703.

44 S. Tatay, P. Gavin, E. Coronado and E. Palomares, Org. Lett., 2006, 8, 3857.

45 E. M. Nolan and S. J. Lippard, J. Am. Chem. Soc., 2003, 125, 14270.

46 T. Mistri, R. Alam, R. Bhowmick, A. Katarkar, K. Chaudhuri and M. Ali, New J. Chem., 2016, 40, 330.

47 M. Suresh, A. Ghosh and A. Das, Chem. Commun., 2008, 3906.

48 H. L. Li, J. L. Fan, F. L. Song, H. Zhu, J. J. Du, S. G. Sun and X. J. Peng, Chem.-Eur. J., 2010, 16, 12349.

49 L. D. Chebrolu, S. Thurakkal, H. S. Balaraman and R. Danaboyina, Sens. Actuators, B, 2014, 8, 204. 